\title{
A JUDICIALIZAÇÃo DA POLÍTICA E A EFETIVIDADE DOS DIREITOS SOCIAIS
}

\author{
JUDICIALIZATION OF POLITICS AND THE EFFECTIVENESS OF SOCIAL \\ RIGHTS
}

Regiane Nistler ${ }^{1}$

SUMÁRIO: Introdução; 1 . Judicialização da política: conceito, características e sua abordagem pelo Supremo Tribunal Federal; 2. Direitos Sociais; 2.1. Características e classificação dos direitos sociais; 3. Influência da judicialização da política na efetividade dos direitos sociais; Considerações finais; Referências das fontes citadas.

\section{RESUMO}

Judicializar a política, em síntese, é quando o Judiciário trata de questões e efetiva direitos que não Ihe competem na condição de poder subsidiário, pois se tratam de tarefas a serem exercidas e efetivadas por políticas públicas do Poder Executivo e abordadas pelo Congresso Nacional, como por exemplo, o acesso a medicamentos pela população e até mesmo a conquista de uma vaga em escola da rede pública de ensino. Ainda, o fenômeno é amplamente discutido e muito criticado, dada a separação dos três poderes e a clara distribuição de competências. Todavia, sem perder a crítica em relação ao tema que é relevante e importante nesse tempo, é preciso abordar a problemática de estar a judicialização da política servindo de grande instrumento de efetivação de inúmeros direitos sociais, pois supõe-se que ela pode estar servindo de caminho para o cumprimento das promessas do Estado Democrático de Direito na Carta Magna de 1988, no que tange aos direitos de natureza social.

PALAVRAS-CHAVE: Judicialização da Política; Direitos Sociais; Efetividade.

\footnotetext{
${ }^{1}$ Mestranda em Direito pelo PPGD da Faculdade Meridional - IMED. Bolsista (taxa) da Coordenação de Aperfeiçoamento de Pessoal do Ensino Superior - CAPES - PROSUP. Especializanda em Direito Empresarial pela Universidade Estácio de Sá. Especialista em Direito e Processo do Trabalho (2015) e graduada em Direito (2013) pela Universidade para o Desenvolvimento do Alto Vale do Itajaí - Unidavi. Líder do Grupo de Pesquisa Direito, Constituição e Sociedade de Risco da Unidavi. Membro do Grupo de Pesquisa Transnacionalismo e Circulação de Modelos Jurídicos do PPGD da Faculdade Meridional - IMED. Associada ao Conselho Nacional de Pesquisa e PósGraduação em Direito - CONPEDI. Professora substituta das disciplinas de Direito Empresarial I e II do curso de Direito da Unidavi. Advogada, OAB/SC. E-mail: regianenistler@outlook.com.
} 
NISTLER, Regiane. A judicialização da política e a efetividade dos direitos sociais. Revista Eletrônica Direito e Política, Programa de Pós-Graduação Stricto Sensu em Ciência Jurídica da UNIVALI, Itajaí, v.11, n.1, $1^{\circ}$ quadrimestre de 2016. Disponível em: www.univali.br/direitoepolitica - ISSN 19807791.

\section{ABSTRACT}

Judicialize politics, in short, is when the judiciary deals with issues and effective rights not you compete in the subsidiary power condition, since these are tasks to be performed and effected by public policy of the Executive Branch and addressed by Congress as for example, access to medicines by the population and even the conquest of a place in school public schools. Still, the phenomenon is widely discussed and criticized, given the separation of the three powers and a clear division of responsibilities. However, without losing critical of the topic that is relevant and important at this time, we must address the problem of being the legalization of politics serving as a great tool for realization of many social rights, because it is assumed that it may be serving path to the fulfillment of the promises of the democratic rule of law in the 1988 Constitution, with respect to the rights of a social nature.

KEYWORDS: Legalization of policy; Social rights; Effectiveness.

\section{INTRODUÇÃO}

Inegável que fixar o sentido e o alcance de uma determinada lei, na sua aplicação a um caso concreto, de algum modo sempre implica poder normativo não muito distinto daquele existente no próprio ato de legislar ${ }^{2}$. Assim, temos como relevante a análise realizada quanto a relação existente entre os universos jurídico e político.

Ocorre que se cria uma problemática trazida pelo paradigma do Estado Democrático de Direito consistente na tensão entre jurisdição e legislação.

Todavia, embora a judicialização da política seja capaz de causar inúmeras discussões no que tange a necessidade de se evitar o fenômeno, observando, em especial, a separação dos três poderes que delimita as competências, imprescindível registar que judicializar questões de natureza política, que deveriam estar sendo efetivadas em outra esfera (Poder Executivo e Legislativo), mas que acabam desaguando no Poder Judiciário tem seus aspectos positivos, como a garantia de direitos, acerca dos quais para a presente pesquisa, frisamse os sociais, previstos na Constituição de 1988.

\footnotetext{
2 FARIA, José Eduardo. Os desafios do Judiciário. Revista USP. Coordenadoria de Comunicação Social (CCS) / USP, 1994. São Paulo, n. 21, p. 47-57.
} 
NISTLER, Regiane. A judicialização da política e a efetividade dos direitos sociais. Revista Eletrônica Direito e Política, Programa de Pós-Graduação Stricto Sensu em Ciência Jurídica da UNIVALI, Itajaí, v.11, n.1, $1^{\circ}$ quadrimestre de 2016. Disponível em: www.univali.br/direitoepolitica - ISSN 19807791.

No que tange aos direitos sociais, amplitude dos temas inscritos no art. $6^{\circ}$ da Constituição deixa claro que os direitos sociais não são somente os que estão enunciados nos artigos 70, 80, 90, 10 e 11. Eles podem ser localizados, principalmente, no Título VIII - Da Ordem Social, artigos 193 e seguintes.

Ademais, é de notório conhecimento que direitos como concessão de medicamentos e vagas em escolas, por exemplo, somente são garantidos em fase judicial, ou seja, o Poder Judiciário, de natureza subsidiária, acaba por fazer o papel primeiro, aquele que seria da implementação efetiva do direito com normas capazes de assegurar a população, bem como, de políticas públicas pelo Poder Executivo. Eis a crítica.

No entanto, a judicialização da política quem sabe esteja sendo um caminho de efetivação dos direitos sociais, rol extenso prometido pela democracia de 1988.

\section{JUDICIALIZAÇÃO DA POLÍTICA: CONCEITO, CARACTERÍSTICAS E SUA ABORDAGEM PELO SUPREMO TRIBUNAL FEDERAL}

A Judicialização da Política tem sido notada nos Estados Unidos, de fato, desde o paradigmático caso Marbury v. Madison, quando a atuação do Poder Judiciário, no controle da constitucionalidade das leis, passou a exercer um papel de destaque na vida política e social daquele país. Apesar disso, foi a partir do século XX que a Suprema Corte norte-americana revelou uma atuação mais explicita em favor da efetivação dos direitos individuais, por meio do acolhimento de teses nesse sentido, notadamente em sede de revisão judicial (o século $X X$, na história da Suprema Corte, apenas para citar - e antecipar - alguns exemplos, for marcado pela Era Lochner e pela lendária Corte Warren). Na verdade, a capacidade de os juízes e de os tribunais estadunidenses influírem no funcionamento das suas instituições é enorme e parece aumentar com o passar do tempo . $^{3}$

\footnotetext{
3 NUNES JUNIOR, Amandino Teixeira. A judicialização da política no contexto da Constituição de 1988. In: ARAÚJO, José Cordeiro de; PEREIRA JÚNIOR, José de Sena; PEREIRA, Lúcio Soares; RODRIGUES, Ricardo José Pereira (Orgs.). Ensaios sobre impactos da Constituição Federal
} 
NISTLER, Regiane. A judicialização da política e a efetividade dos direitos sociais. Revista Eletrônica Direito e Política, Programa de Pós-Graduação Stricto Sensu em Ciência Jurídica da UNIVALI, Itajaí, v.11, n.1, $1^{\circ}$ quadrimestre de 2016. Disponível em: www.univali.br/direitoepolitica - ISSN 19807791.

Todavia, este não é um fenômeno exclusivo ou particular do modelo norteamericano; pelo contrário, o constitucionalismo europeu, notadamente no segundo pós-guerra, também passou a apresentar característica bastante ampliativa da atuação dos Tribunais Constitucionais, vindo de fenômenos como constitucionalização do direito, eficácia horizontal e vertical dos direitos fundamentais, ampliação (e "reforço", pois os Tribunais Constitucionais, apesar de já existirem antes disso, ganham novo ânimo após os regimes totalitários, sendo a grande "aposta" para a preservação dos direitos fundamentais contidos nos textos constitucionais) dos instrumentos de controle de constitucionalidade, ampliação dos conteúdos constitucionais, ampliação dos direitos fundamentais, etc. ${ }^{4}$.

Assim, importante lembrar a secular relação de alternância de dominação: ora do Direito sobre a política, ora desta sobre aquele, cuja necessidade de equilíbrio (para que o poder fosse, ao mesmo tempo, racional e exercido de forma limitada) encontrou resposta na Constituição, que é direito positivo (determinado pelo homem e não como um dado da natureza), mas também contempla exigências de conteúdo (direitos constitucionais vinculantes) a serem observados (e impõe limites à política).$^{5}$

Desta forma, pode-se afirmar que a Constituição é, como pondera Streck, o "elo conteudístico" que une "política e direito" na conformação do Estado6, confirmando a intuição de Barroso de que constitucionalizar uma matéria é, na verdade, transformar a Política em Direito ${ }^{7}$.

de 1988 na sociedade brasileira: consultoria legislativa. Brasília: Centro de Documentação e Informação, 2008. p. 755.

4 GERVASONI, Tássia Aparecida. LEAL, Mônia Clarissa Hennig. Judicialização da política e ativismo judicial na perspectiva do Supremo Tribunal Federal. Curitiba: Multideia, 2013.p. 75.

5 GRIMM, Dieter. Constituição e política. Tradução de Geraldo de Carvalho. Coordenação e supervisão de Luiz Moreira Belo Horizonte: Del Rey, 2006. p. 3 - 10.

6 STRECK, Lenio Luiz. Jurisdição constitucional e hermenêutica: uma nova crítica do Direito. Porto Alegre: Livraria do Advogado, 2002. p. 105.

7 BARROSO, Luís Roberto. Judicialização, ativismo judicial e legitimidade democrática. Disponível

em:

<http://www.oab.org.br/editora/revista/users/revista/1235066670174218181901.pdf> Acesso em: 01 jul. 2015. 
NISTLER, Regiane. A judicialização da política e a efetividade dos direitos sociais. Revista Eletrônica Direito e Política, Programa de Pós-Graduação Stricto Sensu em Ciência Jurídica da UNIVALI, Itajaí, v.11, n.1, $1^{\circ}$ quadrimestre de 2016. Disponível em: www.univali.br/direitoepolitica - ISSN 19807791.

De todo modo, verifica-se uma infinidade de discussões no que tange a (in) separabilidade desses dois sistemas e das interferências recíprocas que podem ou não ser admitidas, sendo o deslinde desse quadro e, em especial, a fixação de algumas diferenças terminológicas, o primeiro passo para a delimitação conceitual da judicialização da política.

No contexto do positivismo jurídico passou-se a considerar "Direito" o que está inserido no texto da lei, a qual na situação atual é feita segundo o jogo das forças políticas, especialmente considerando-se seu âmbito de origem: o Poder Legislativo. Daí que o termo política incorporou uma conotação muito próxima das ações de natureza político-partidária e a lei, por sua vez, passou a ser expressão da vontade do grupo que predomina em determinado momento na vida de um povo - a maioria (ainda que seja muitas vezes um instrumento de interesses individuais ou grupais contrários aos do próprio povo) ${ }^{8}$.

Nesse sentido, repisa-se a problemática implícita trazida pelo paradigma do Estado Democrático de Direito consistente na tensão entre jurisdição e legislação. Ocorre que as normas jurídicas e, em especial, as normas constitucionais, em muitos casos não podem ser interpretadas sem o recurso a valorações politicas, porém, tais valorações são, em regra, subjetivas / pessoais (daí a mencionada relação tensionante entre o Direito e a política, já que, não obstante o juiz constitucional aplique o Direito, a sua aplicação conduz a valorações politicas) ${ }^{9}$.

De todo modo, sustenta-se que os juízes exercem atividade política em diferentes sentidos: por serem integrantes do aparato de poder do Estado, que é uma sociedade política, e por aplicarem normas do Direito, que são necessariamente politicas. Ainda, antes de tudo, o juiz é cidadão e, portanto, também vota. Assim, não se pode ignorar que possui suas próprias preferências políticas, embora não as externe por considerar-se "apolítico", condição que se reputa indispensável para o reconhecimento de sua imparcialidade e

\footnotetext{
${ }^{8}$ DALLARI, Dalmo de Abreu. O poder dos juízes. São Paulo: Saraiva. 1996. p. 57.

9 STRECK, Lenio Luiz. Jurisdição constitucional e hermenêutica: uma nova crítica do Direito. Porto Alegre: Livraria do Advogado, 2002. p. 102.
} 
NISTLER, Regiane. A judicialização da política e a efetividade dos direitos sociais. Revista Eletrônica Direito e Política, Programa de Pós-Graduação Stricto Sensu em Ciência Jurídica da UNIVALI, Itajaí, v.11, n.1, $1^{\circ}$ quadrimestre de 2016. Disponível em: www.univali.br/direitoepolitica - ISSN 19807791.

independência. Isso se deve, contudo, ao equivoco de se atribuir à palavra "política" o sentido estreito de "politica partidária". No entanto, a título de adendo, todos os juízes fazem opções político-eleitorais, sendo preferível reconhecer isso que fingir uma neutralidade absoluta, que seria sinônimo de indiferença pelos destinos do país e da comunidade, inaceitável em qualquer cidadão. Esse é apenas um dos aspectos da policiticidade. ${ }^{10}$

De outro lado, a separação entre Direito e política pressupõe uma vinculação legal que se revela problemática no atual estágio de complexidade das relações sociais. Há uma exigência implícita de que a política forneça realmente programas decisórios a aplicação do Direito, por meio dos quais possam ser resolvidos, no âmbito do Judiciário, os conflitos instaurados. O que se verifica na prática, contudo, é uma extrema dificuldade de se manter essa regulamentação atualizada. Isso se deve, basicamente, a dois fatores: a) ao fracasso parcial do auto redirecionamento da sociedade por meio do mercado, que precisou ser substituído pela regulamentação estatal (em níveis extremamente altos); e b) a acelerada mudança social, que aumenta a velocidade com a qual o direito existente envelhece e reclama substituição (ou atualização). Descritos elementos tornam complexa essa atividade estatal, que já não consegue se antecipar por completo $e$, consequentemente, não pode oferecer uma regulamentação de forma normativa ${ }^{11}$.

A propósito, a pretensão de autonomia absoluta do Direito em relação à política é impossível de se realizar, haja vista que as soluções para os casos concretos nem sempre (se não raramente) são encontradas prontas no ordenamento jurídico, mas precisam ser construídas argumentativamente por juízes e tribunais. Nesses casos, a experiência demonstra que os valores de natureza pessoal e a ideologia do intérprete desempenham, conscientemente ou não, papel decisivo nas suas conclusões ${ }^{12}$.

\footnotetext{
${ }^{10}$ DALLARI, Dalmo de Abreu. O poder dos juízes. São Paulo: Saraiva. 1996. p. 85 e 87.

${ }^{11}$ GRIMM, Dieter. Constituição e política. Tradução de Geraldo de Carvalho. Coordenação e supervisão de Luiz Moreira Belo Horizonte: Del Rey, 2006. p. 17 - 18.

12 BARROSO, Luis Roberto. Constituição, democracia e supremacia judicial: direito e política 
NISTLER, Regiane. A judicialização da política e a efetividade dos direitos sociais. Revista Eletrônica Direito e Política, Programa de Pós-Graduação Stricto Sensu em Ciência Jurídica da UNIVALI, Itajaí, v.11, n.1, $1^{\circ}$ quadrimestre de 2016. Disponível em: www.univali.br/direitoepolitica - ISSN 19807791.

Importante destacar a advertência acerca do caráter eminentemente político da jurisdição constitucional, cuja elucidação ora se vale das constatações de Queiroz no sentido de que não se pode confundir o caráter (objeto) político da jurisdição constitucional com uma atuação de cunho político, tendo em vista que sua atuação, apesar do caráter político, deve ser jurídica ${ }^{13}$.

No entanto, uma coisa é a justiça constitucional poder refletir-se indiretamente na política, influenciando a toada das decisões políticas e outra bem distinta é que passe conscientemente a atuar funções de "indirizzo politico" em todas ou algumas de suas decisões principais. O "indirizzo político" seria a síntese da constituição atuada, uma espécie de "direito constitucional constituído", um "direito constitucional concretizado". Nesta última hipótese, os tribunais de justiça constitucional não desenvolveriam uma atividade política "stricto sensu", não podendo por isso ser considerados como "co-legisladores" antes procederia a uma "atuação constitucional" com o fim de revelar o diálogo entre as instâncias legislativas e o poder judicial ${ }^{14}$.

Desta forma, o conceito trazido por Barroso é esclarecedor, no sentido de que a

Judicialização significa que algumas questões de larga repercussão política ou social estão sendo decididas por órgãos do Poder Judiciário, e não pelas instâncias políticas tradicionais: o Congresso Nacional e o Poder Executivo. Como intuitivo, a judicialização envolve uma transferência de poder para juízes e tribunais, com alterações significativas na linguagem, na argumentação e no modo de participação da sociedade ${ }^{15}$.

http://www.oab.org.br/editora/revista/revista_11/artigos/constituicaodemocraciaesupremaciajudi cial.pdf> Acesso em: 10 jul. 2015.

13 GERVASONI, Tássia Aparecida. LEAL, Mônia Clarissa Hennig. Judicialização da política e ativismo judicial na perspectiva do Supremo Tribunal Federal. Curitiba: Multideia, 2013.p. 84.

14 GERVASONI, Tássia Aparecida. LEAL, Mônia Clarissa Hennig. Judicialização da política e ativismo judicial na perspectiva do Supremo Tribunal Federal. Curitiba: Multideia, 2013.p. 83.

15 BARROSO, Luís Roberto. Judicialização, ativismo judicial e legitimidade democrática. Disponível <http://www.oab.org.br/editora/revista/users/revista/1235066670174218181901.pdf> Acesso em: 01 jul. 2015. 
NISTLER, Regiane. A judicialização da política e a efetividade dos direitos sociais. Revista Eletrônica Direito e Política, Programa de Pós-Graduação Stricto Sensu em Ciência Jurídica da UNIVALI, Itajaí, v.11, n.1, $1^{\circ}$ quadrimestre de 2016. Disponível em: www.univali.br/direitoepolitica - ISSN 19807791.

O fenômeno em apreço tem causas diversas (as quais, de certa forma são "externas" ao Judiciário, isto é, decorrem de outros fatores que escapam ao seu controle), das quais pelo menos três merece destaque, quais sejam: a primeira grande causa da judicialização ("olhando" para a realidade brasileira), foi a redemocratização do país, que teve como ponto culminante a promulgação da Constituição de 1988, já que, em síntese, esse processo fortaleceu e expandiu o Poder Judiciário, bem como aumentou a demanda por justiça na sociedade brasileira; a segunda causa foi a constitucionalização abrangente, que trouxe para a Constituição inúmeras matérias que antes eram deixadas para o processo político majoritário e para a legislação ordinária e agora passam a ser tratadas (pelo menos há essa possibilidade em sede jurisdicional; e, por fim, a terceira, e última causa a ser destacada, é o sistema brasileiro de controle de constitucionalidade, um dos mais abrangentes do mundo, possibilitando que quase qualquer questão política ou moralmente relevante possa ser alçada ao Supremo tribunal Federal ${ }^{16}$.

Um primeiro sentido em que a Suprema Corte brasileira refere-se a locução "judicialização" mostra-se distante daquele que tem agitado os bancos acadêmicos e acalorado os debates políticos. Trata-se da singela e quase literal significação de judicialização como matéria judicializada, ou seja, posta em juízo por meio de um processo judicial. Esse sentido teria sido constatado em um acordão, trinta e duas decisões monocráticas e dois informativos ${ }^{17}$.

Diferentemente ocorre, por exemplo, quanto à segunda significação encontrada na jurisprudência do STF, que faz menção a um tema bastante específico, avançando rumo aos conceitos lançados anteriormente. Trata-se da ideia de judicialização do direito à saúde - sendo que no referido sentido foram

16 BARROSO, Luís Roberto. Judicialização, ativismo judicial e legitimidade democrática. Disponível

<http://www.oab.org.br/editora/revista/users/revista/1235066670174218181901.pdf> Acesso em: 01 jul. 2015.

17 GERVASONI, Tássia Aparecida. LEAL, Mônia Clarissa Hennig. Judicialização da política e ativismo judicial na perspectiva do Supremo Tribunal Federal. Curitiba: Multideia, 2013.p. 127. 
NISTLER, Regiane. A judicialização da política e a efetividade dos direitos sociais. Revista Eletrônica Direito e Política, Programa de Pós-Graduação Stricto Sensu em Ciência Jurídica da UNIVALI, Itajaí, v.11, n.1, $1^{\circ}$ quadrimestre de 2016. Disponível em: www.univali.br/direitoepolitica - ISSN 19807791.

identificados dois acórdãos ${ }^{18}$; vinte e quatro decisões da Presidência; e sete decisões monocráticas - pela qual se passa todo um debate acerca da atuação do Poder Judiciário na implementação dos direitos sociais, o que, por sua vez, traz à tona a problemática sobre a efetividade desses direitos, a sua realização mediante políticas públicas, a natureza de suas normas consagradoras e as suas respectivas competências para tanto, com reflexos diretos na teoria da separação de Poderes.

Ou seja, o Poder Judiciário acaba por efetivar as políticas públicas ou até mesmo substitui-las, à medida que finalmente faz valer direitos elementares a população, por exemplo, e em especial (para o presente estudo), os direitos sociais previstos na Constituição de 1988.

\section{DIREITOS SOCIAIS}

Os direitos sociais têm por objetivo garantir aos indivíduos condições materiais tidas como imprescindíveis para o pleno gozo dos seus direitos, por isso tendem a exigir do Estado uma intervenção na ordem social que garanta os critérios de justiça distributiva, assim diferentemente dos direitos a liberdade, se realizam por meio de atuação estatal com a finalidade de diminuir as desigualdades sociais.

Por volta do século XIX, nasce a substituição do homem pela máquina, gerando grande índice de desemprego, miséria e mão-de-obra excedente, causando desigualdade social, fazendo com que o Estado se visse diante da necessidade de proteção ao trabalho e a outros direitos como: saúde, educação, lazer, alimentação, trabalho, moradia, segurança, entre outros.

Entretanto, os direitos sociais tiveram realmente sua plenitude com o marxismo e o socialismo revolucionário, já no século $X X$ que trouxe uma nova concepção

\footnotetext{
${ }^{18}$ SL 47 Agr., Relator(a): Min. Gilmar Mendes (Presidente), Tribunal Pleno, julgado em 17.03.2010, DJe-076 Divulg. 29.04.2010. Public. 30.04.2010 Ement vol-02399-01 PP-00001; e STA 175 AgR, Relator(a): Min. Gilmar Mendes (Presidente), Tribunal Pleno, julgado em 17.03.2010, DJe-076 Divulg 29.04.2010 Public 30.04.2010 Ement vol-02399-01 PP 00070.
} 
NISTLER, Regiane. A judicialização da política e a efetividade dos direitos sociais. Revista Eletrônica Direito e Política, Programa de Pós-Graduação Stricto Sensu em Ciência Jurídica da UNIVALI, Itajaí, v.11, n.1, $1^{\circ}$ quadrimestre de 2016. Disponível em: www.univali.br/direitoepolitica - ISSN 19807791.

de divisão do trabalho e do capital, por isso entende-se que os direitos sociais foram aceitos nos ordenamentos jurídicos por uma questão política, e não social isso é para evitar que o socialismo acabasse por derrubar o capitalismo.

Todavia, a declaração de direitos nas Constituições teve como marco inicial a Constituição Mexicana de 1917, no qual a ordem social, como a ordem econômica, adquiriu dimensão jurídica, pois passaram a disciplina-la sistematicamente.

No Brasil, a primeira Constituição a apresentar um título sobre a ordem econômica e social foi a de 1934, sob a influência da famosa Constituição de Weimar (1919), o que perdurou nas Constituições posteriores. ${ }^{19}$

O artigo $6^{\circ}$ da Constituição Federal de 1988 se refere de maneira bastante abrangente quanto aos direitos sociais por excelência, como o direito a saúde, ao trabalho, ao lazer, a educação, a alimentação, a moradia, a segurança, a previdência social, a proteção à maternidade e a infância, a previdência social e assistência aos desamparados.

Examinando a partir disso, pressupõe-se que os direitos sociais buscam a qualidade de vida dos cidadãos, no entanto apesar de estarem interligados faz-se necessário, ressaltar e distinguir as diferenças entre direitos sociais e direitos individuais. Portando os direitos sociais, como dimensão dos direitos fundamentais do homem, são prestações positivas proporcionadas pelo Estado direta ou indiretamente, enunciadas em normas constitucionais, que possibilitam melhores condições de vida aos mais fracos, direitos que tendem a realizar a equalização de situações sociais desiguais, são, portanto, direitos que se ligam ao direito de igualdade.

Na sua grande maioria, o atendimento aos referidos direitos sociais exige uma atuação do Estado, razão pela qual grande parte dessas normas é de eficácia limitada. Importante destacar que a implementação desses direitos ocorre mediante políticas públicas concretizadoras de certas prerrogativas individuais

19 SILVA, José Afonso da. Curso de Direito Constitucional Positivo. 30a Ed., São Paulo: Malheiros Editores, 2008. p. 285. 
NISTLER, Regiane. A judicialização da política e a efetividade dos direitos sociais. Revista Eletrônica Direito e Política, Programa de Pós-Graduação Stricto Sensu em Ciência Jurídica da UNIVALI, Itajaí, v.11, n.1, $1^{\circ}$ quadrimestre de 2016. Disponível em: www.univali.br/direitoepolitica - ISSN 19807791.

e/ou coletivas, destinadas a reduzir as desigualdades sociais existentes e a garantir uma existência humana digna ${ }^{20 .}$

Alexandre de Moraes afirma que, os direitos sociais fundamentais do homem, caracterizam-se como verdadeiras liberdades positivas, de observância obrigatória de um Estado Social de Direito, tendo por finalidade a melhoria de condições de vida hipossuficientes, visando à concretização da igualdade social, e são consagrados como fundamentos do Estado democrático, peto art. 10, inc. IV da Constituição Federal de $1988^{21}$.

Aponta, ainda, que os direitos sociais dos cidadãos são genéricos e abstratos e existem também os direitos sociais do trabalhador, os quais se encontram dispostos no art. 70 da Constituição Federal de 1988, tais direitos apresentam conceito infraconstitucional. O autor conceitua trabalhador aquele que trabalha ou presta serviços por conta sob direção da autoridade de outrem, pessoa física ou jurídica, entidade privada ou pública 22.

Argumenta, também, que os direitos sociais são normas de ordem pública, com a característica de imperativas, invioláveis, portanto, pela vontade das partes contraentes da relação trabalhista ${ }^{23}$.

Nesse sentido, José Afonso da Silva, define os direitos sociais, como dimensões dos direitos fundamentais do homem, são prestações positivas proporcionadas pelo Estado direta e indiretamente, enunciadas em normas constitucionais, que possibilitam melhores condições de vida aos mais fracos, direitos que tendem a realizar a igualização de situações sociais desiguais ${ }^{24}$.

Finaliza indicando que são direitos que se ligam ao direito de igualdade. Equivalem como pressupostos do gozo dos direitos individuais na medida em que

20 NOVELINO, Marcelo. Manual de Direito Constitucional. 9 Ed. rev. e atual, Rio de Janeiro: Forense; São Paulo: MÉTODO, 2014. p. 619.

${ }^{21}$ MORAES, Alexandre de. Direito Constitucional, 26 ed. São Paulo: Atlas, 2010. p. 197

22 MORAES, Alexandre de. Direito Constitucional, p. 197.

${ }^{23}$ MORAES, Alexandre de. Direito Constitucional, p. 197.

24 SILVA, José Afonso da. Curso de Direito Constitucional Positivo. 30a ed., São Paulo: Malheiros Editores, 2008. p. 286-287. 
NISTLER, Regiane. A judicialização da política e a efetividade dos direitos sociais. Revista Eletrônica Direito e Política, Programa de Pós-Graduação Stricto Sensu em Ciência Jurídica da UNIVALI, Itajaí, v.11, n.1, $1^{\circ}$ quadrimestre de 2016. Disponível em: www.univali.br/direitoepolitica - ISSN 19807791.

criam condições materiais mais propícias ao aferimento da igualdade real, o que proporciona condição mais compatível com o exercício efetivo da liberdade ${ }^{25}$.

\subsection{CARACTERÍSTICAS E CLASSIFICAÇÃO DOS DIREITOS SOCIAIS}

A Constituição de 1988 estabelece no artigo 60, que "são direitos sociais a educação, a saúde, o trabalho, a moradia, o lazer, a segurança, a previdência social, a proteção à maternidade e à infância, a assistência aos desamparados, na forma desta Constituição ${ }^{26}$."

A amplitude dos temas inscritos no art. $6^{\circ}$ da Constituição deixa claro que os direitos sociais não são somente os que estão enunciados nos artigos $70,8^{\circ}, 90$, 10 e 11 . Eles podem ser localizados, principalmente, no Título VIII - Da Ordem Social, artigos 193 e seguintes.

José Afonso da Silva classifica os direitos sociais à luz do Direito positivo, agrupando em seis classes, sendo elas:

a) Direitos sociais relativos ao trabalhador; b) direitos sociais relativos à seguridade, compreendendo os direitos à saúde, à previdência e assistência social; c) direitos sociais relativos à educação e cultura; d) direitos sociais relativos à moradia; e) direitos sociais relativos à família, criança, adolescente e idoso; f) direitos sociais relativos ao meio ambiente ${ }^{27}$.

Relata em sua obra, que há uma classificação dos direitos sociais do homem como produtor e como consumidor, entram na primeira categoria: a liberdade de instituição sindical, o direito de greve, o direito de o trabalhador determinar as condições do seu trabalho, o direito de cooperar na gestão da empresa e o direito de obter emprego (artigos 70 a 11 da Constituição Federal de 1988) ${ }^{28}$.

${ }^{25}$ SILVA, José Afonso da. Curso de Direito Constitucional Positivo. 30a ed., São Paulo: Malheiros Editores, 2008. p. 286-287.

${ }^{26}$ BRASIL. Constituição da República Federativa do Brasil: promulgada em 5 de outubro de 1988 / obra coletiva de autoria da Editora Saraiva com a colaboração de Antonio Luiz de Toledo Pinto. Marcia Cristina Vaz dos Santos Windt e Lívia Céspedes. 45 ed. atual. e ampl. São Paulo: Saraiva. 2011.

27 SILVA, José Afonso da. Curso de Direito Constitucional Positivo. p. 286-287.

${ }^{28}$ SILVA, José Afonso da. Curso de Direito Constitucional Positivo. p. 286-287. 
NISTLER, Regiane. A judicialização da política e a efetividade dos direitos sociais. Revista Eletrônica Direito e Política, Programa de Pós-Graduação Stricto Sensu em Ciência Jurídica da UNIVALI, Itajaí, v.11, n.1, $1^{\circ}$ quadrimestre de 2016. Disponível em: www.univali.br/direitoepolitica - ISSN 19807791.

No tocante aos direitos sociais do homem consumidor listou os seguintes: os direitos à saúde, à segurança social, ao desenvolvimento intelectual, o igual acesso das crianças e adultos à instrução, à formação profissional e à cultura e garantia ao desenvolvimento da família, que são os indicados no artigo $60^{29}$.

Por ser didática, facilitando o entendimento, mencionamos essa classificação. Os direitos sociais relativos ao trabalhador são de duas espécies:

a) os direitos dos trabalhadores em suas relações individuais de trabalho: CF de 88, art. 70; b) os direitos coletivos dos trabalhadores: CF de 88, arts. 90 a 11. Os direitos sociais relativos à seguridade, compreendendo os direitos à saúde, à previdência e assistência social, estão no título da Ordem Social, artigos 193 e seguintes ${ }^{30}$.

Os direitos sociais relativos à família, criança, adolescente e idoso poderão ser encontrados em capítulos da Ordem Social: art. 201, inc. II, art. 203, inc. I, II, arts. 226 e 227, art. 230. Finalmente, nos direitos sociais relativos ao meioambiente, deve ser incluído o direito ao lazer (CF de 88, art. 60, art. 227) e ao meio ambiente ecologicamente equilibrado, bem de uso comum do povo e essencial à sadia qualidade de vida, impondo-se ao poder público e à coletividade o dever de defendê-lo e preservá-lo para as presentes e futuras gerações (C.F., art. 225). O direito ao meio ambiente integra a disciplina urbanística. Constitui, também, espécie de interesse difuso, direito fundamental de $3^{a}$ geração ${ }^{31}$.

A Constituição Federal de 1988 teve grande preocupação quanto aos direitos sociais, estabelecendo uma série de dispositivos que assegurassem ao cidadão todo o básico necessário para uma vida digna e para que tenha condições de trabalho e emprego ideais. Em suma, todas as formalidades para que se determinasse um Estado de bem-estar social do cidadão foram realizadas, e estão descritas na Constituição Federal de 1988.

\footnotetext{
29 SILVA, José Afonso da. Curso de Direito Constitucional Positivo. p. 287.

30 SILVA, José Afonso da. Curso de Direito Constitucional Positivo. p. 286-287.

${ }^{31}$ SILVA, José Afonso da. Curso de Direito Constitucional Positivo. p. 288.
} 


\section{INFLUÊNCIA DA JUDICIALIZAÇÃo DA POLÍtICA NA EFETIVIDADE DOS DIREITOS SOCIAIS}

Inegável que fixar o sentido e o alcance de uma determinada lei, na sua aplicação a um caso concreto, de algum modo sempre implica poder normativo não muito distinto daquele existente no próprio ato de legislar ${ }^{32}$. Assim, temos como relevante a análise realizada quanto a relação existente entre os universos jurídico e político.

Ainda, embora esse contexto seja intitulado de "judicialização da política" e capaz de ensejar inúmeras discussões no que tange a necessidade de se evitar o fenômeno, observando, em especial, a separação de poderes em seu conceito original, diga-se na perspectiva de Montesquieu, imprescindível registar que judicializar questões de natureza política, que deveriam estar sendo efetivadas em outra esfera (Poder Executivo e Legislativo), mas que acabam desaguando no Poder Judiciário tem seus aspectos positivos, como a garantia de direitos, acerca dos quais para a presente pesquisa, frisam-se os sociais, previstos na Constituição de 1988.

Aliás, já afirmou Celso de Mello, que - "é a necessidade de fazer valer a Constituição, muitas vezes transgredida e desrespeitada por pura, simples e conveniente omissão dos poderes públicos" - que, dentre outras causas, justifica "esse comportamento afirmativo do Poder Judiciário"33. Extrai-se, assim, do voto em exame, que apreciava caso de direito a saúde, que o entendimento da efetivação do respectivo direito pela jurisdição constitucional (inclusive mediante a determinação de políticas públicas), quando supre omissões inconstitucionais dos órgãos competentes, nada mais é do que o cumprimento de uma missão institucional, em demonstração de respeito incondicional a Constituição; ou seja, na verdade, o Supremo Tribunal Federal, ao adotar tais medidas de ordem "afirmativa" sustenta que objetiva apenas restaurar a ordem (constitucional) violada pela inércia dos demais Poderes (cuja omissão, inclusive, o Ministro

\footnotetext{
32 FARIA, José Eduardo. Os desafios do Judiciário. Revista USP. Coordenadoria de Comunicação Social (CCS) / USP, 1994. São Paulo, n. 21, p. 47-57.

33 BRASIL. Supremo Tribunal Federal. SL 47 AgR, Relator: Min. Gilmar Mendes (Presidente), Tribunal Pleno, julgado em 17 mar. 2010.
} 
NISTLER, Regiane. A judicialização da política e a efetividade dos direitos sociais. Revista Eletrônica Direito e Política, Programa de Pós-Graduação Stricto Sensu em Ciência Jurídica da UNIVALI, Itajaí, v.11, n.1, $1^{\circ}$ quadrimestre de 2016. Disponível em: www.univali.br/direitoepolitica - ISSN 19807791.

qualifica como uma das causas geradoras dos processos informais de mudança da Constituição, que deve ser repelido $)^{34}$.

O sistema judicial, desde a promulgação da Constituição Federal de 1988, vem presenciando a expansão tanto do escopo dos direitos sociais quanto de um padrão descentralizado de intervenção pública na área social, envolvendo, inclusive, significativas mudanças na estrutura tributária e nas atribuições do Estado. Tais alterações, no entanto, por vezes não conseguem ser implementadas por falta de leis complementares e/ou por uma forma extremamente formal de administração da justiça, "a ponto de não se preocupar com a solução dos litígios de modo a um só tempo legal, eficaz e legítimo" ${ }^{35}$.

Eis aí, de modo esquemático, o dilema hoje enfrentado pelo Judiciário brasileiro, ao menos em suas instâncias inferiores: cobrir o fosso entre esse sistema jurídico-positivo e as condições de vida de uma sociedade com 40\% de seus habitantes vivendo abaixo da linha da pobreza, em condições subumanas, na consciência de que a atividade judicial extravasa os estreitos limites do universo legal, afetando o sistema social, político e econômico na sua totalidade. Com a expansão dos direitos humanos, que nas últimas décadas perderam seu sentido "liberal" originário e ganharam uma dimensão "social", ficou evidente que pertencer a uma dada ordem político-jurídica é, também, desfrutar do reconhecimento da "condição humana". Quando essas condições não são efetivamente dadas, os segmentos mais desfavorecidos se tornam parias. Esse tem sido o grande paradoxo dos direitos humanos - e também dos direitos sociais - no Brasil: apesar de formalmente consagrados pela Constituição, em termos concretos eles quase nada valem quando os homens historicamente localizados se veem reduzidos à mera condição genérica de "humanidade"; portanto, sem a proteção efetiva de um Estado capaz de identificar as diferenças e as singularidades dos cidadãos, de promover justiça social, de corrigir as

\footnotetext{
34 GERVASONI, Tássia Aparecida. LEAL, Mônia Clarissa Hennig. Judicialização da política e ativismo judicial na perspectiva do Supremo Tribunal Federal. Curitiba: Multideia, 2013.p. 132.

35 FARIA, José Eduardo. Os desafios do Judiciário. Revista USP. Coordenadoria de Comunicação Social (CCS) / USP, 1994. São Paulo, n. 21, p. 48.
} 
NISTLER, Regiane. A judicialização da política e a efetividade dos direitos sociais. Revista Eletrônica Direito e Política, Programa de Pós-Graduação Stricto Sensu em Ciência Jurídica da UNIVALI, Itajaí, v.11, n.1, $1^{\circ}$ quadrimestre de 2016. Disponível em: www.univali.br/direitoepolitica - ISSN 19807791.

disparidades econômicas e de neutralizar uma iníqua distribuição tanto de renda quanto de prestígio e de conhecimento ${ }^{36}$.

O poder hermenêutico do juiz é fundamental na construção do sentido ao ser imprimido ao ordenamento jurídico, sendo que o termômetro do desgaste de um sistema judicial é o próprio Judiciário posto que é o poder responsável por exercer a função de decidir, concretizando as normas abstratas, atendendo, assim, as demandas reais e históricas nas quais agentes sociais se encontram envolvidos. Trazendo este tema para um enfoque a partir da realidade brasileira, temos que o Poder Judiciário é aquele que mais se vê acossado pela enormidade dos problemas, sendo constantemente instigado a decidir conflitos de natureza social, que deveriam ser tratados e implementados politicamente (a priori), e não jurisdicionalmente (a posteriori), diga-se de passagem, lidando com questões dessa natureza dentro de uma cultura liberal, de conflitos individuais, de demandas de interesse privado, sem aparelhamento e/ou preparo devidos, bem como dentro de um sistema engessado por formalismos e procedimentos processuais incapazes de satisfazer a questões de dimensão difusa e/ou coletiva ${ }^{37}$.

No entanto, embora persista a crítica é inegável que o Poder Judiciário exerce papel imprescindível na sociedade nos dias de hoje. Por essa razão, mostra-se acertada a afirmação de que o progresso da democracia mede-se especialmente pela ampliação dos direitos e pela sua afirmação em juízo.

A multiplicação de subsistemas jurídicos diferenciados e que rejeitam a intervenção do Direito estatal traz consigo uma perigosa arma de invalidação do Direito por meio de ameaças privadas. A universalização dos direitos sociais é trocada pelo favorecimento de setores sociais específicos. Se a ordem jurídica aspirar à supressão de seus vazios de eficácia, longe do caminho da regulação auto referencial, poderá encontrar no resgate da norma jurídica um importante critério objetivo de redistribuição de direitos e de justiça social. Daí a importância, para a consolidação da

\footnotetext{
${ }^{36}$ FARIA, José Eduardo. Os desafios do Judiciário. p. 48.

37 BITTAR, Educado Carlos Bianca. O direito na pós-modernidade. Rio de Janeiro: Forense Universitária, 2005. p. $47-48$.
} 
NISTLER, Regiane. A judicialização da política e a efetividade dos direitos sociais. Revista Eletrônica Direito e Política, Programa de Pós-Graduação Stricto Sensu em Ciência Jurídica da UNIVALI, Itajaí, v.11, n.1, $1^{\circ}$ quadrimestre de 2016. Disponível em: www.univali.br/direitoepolitica - ISSN 19807791.

democracia entre nós, da afirmação de um Judiciário sintonizado com as características do seu tempo ${ }^{38}$.

Em todo caso, é própria do contexto contemporâneo de cultura democrática, a projeção do papel do juiz em quase todos os aspectos da vida social. Essa projeção, todavia, não tem derivado como em certas avaliações apressadas, de pretensões do próprio Judiciário. Antes, pelo contrário, o fato de que os juízes, crescentemente, ocupem lugares tradicionalmente reservados as instituições especializadas da política e as de auto regulação social, longe de significar ambições de poder por parte do Judiciário, aponta para processos mais complexos e permanentes que os limites de uma abordagem como essa não permitem aprofundar ${ }^{39}$.

Por derradeiro, talvez valha parafrasear Dino de Castro e Costa no sentido de que os juízes não podem tudo, nem devem poder. Mas podem muito, e devem exercer esse poder em favor da grandiosa e inesgotável utopia de construção da felicidade de cada um e de todos, o que serve para os direitos sociais, pois sem prejuízo da crítica ao instituto da judicialização da política que não se quer suprimir, motivo pelo qual foi amplamente abordada, o fenômeno pode estar servindo para finalmente efetivar direitos prometidos na Constituição de 1988, promulgada na democracia, que como se sabe, costuma prometer muito mais do que pode cumprir.

\section{CONSIDERAÇÕES FINAIS}

Ao longo dos tempos, o Poder Judiciário vem passando por inúmeras transformações no perfil de sua atuação. Nesse sentido, a promulgação do texto constitucional de 1988 simbolizou um momento de uma radical modificação na forma como era concebido o exercício da jurisdição constitucional no Brasil. Em

${ }^{38}$ CAMPILONGO, Celso Fernandes. O Judiciário e a democracia no Brasil. Revista USP. São Paulo, n. 21, p. 124 - 125: Coordenadoria de Comunicação Social (CCS) / USP, 1994.

39 GERVASONI, Tássia Aparecida. LEAL, Mônia Clarissa Hennig. Judicialização da política e ativismo judicial na perspectiva do Supremo Tribunal Federal. Curitiba: Multideia, 2013.p. 90. 
NISTLER, Regiane. A judicialização da política e a efetividade dos direitos sociais. Revista Eletrônica Direito e Política, Programa de Pós-Graduação Stricto Sensu em Ciência Jurídica da UNIVALI, Itajaí, v.11, n.1, $1^{\circ}$ quadrimestre de 2016. Disponível em: www.univali.br/direitoepolitica - ISSN 19807791.

resumo, é possível afirmar que a partir de então uma das expressões que passou a estar diretamente ligada à atividade jurisdicional é "judicialização da política"40.

A definição do termo, de forma simples e objetiva, significa dizer a judicialização de questões políticas. Isso mesmo. Direitos e questões que deveriam ser tratados com efetividade e garantidos na esfera legislativa e principalmente na executiva, com a criação e execução de políticas públicas acaba por desaguar no Poder Judiciário, que em vez de atuar como o Poder subsidiário, acaba por ser a esperança de implementação dos direitos mais elementares.

Aliás, exemplo perfeito e inevitável de ser tratado nesse contexto é os direitos sociais, rol expressivo constante da Constituição Federal de 1988, valendo citar o direito à saúde, alimentação e educação, que muitas vezes somente são garantidos por determinação judicial.

Ou seja, em que pese exista grande volume de críticas ao instituto da judicialização da politica, tendo em vista a separação de poderes de Montesquieu e até mesmo o transpasse dos limites de competência dos juízes, o que pode ensejar outros fenômenos e diversos longos ensaios, é inegável que judicializar questões politicas pode estar sendo uma saída para a garantia e efetividade dos direitos sociais prometidos na carta democrática de 1988, que muito prometeu nesse sentido, mas tem falhado ao cumprir.

\section{REFERÊNCIAS DAS FONTES CITADAS}

BARROSO, Luís Roberto. Judicialização, ativismo judicial e legitimidade democrática. Disponível em: <http://www.oab.org.br/editora/revista/users/revista/123506667017421818190 1.pdf> Acesso em: 01 jul. 2015.

BITTAR, Educado Carlos Bianca. O direito na pós-modernidade. Rio de Janeiro: Forense Universitária, 2005. p. 47 - 48.

40 TASSINARI. Clarissa. Jurisdição e Ativismo Judicial: limites da atuação do judiciário. Porto Alegre: Livraria do Advogado, 2013. p. 27. 
NISTLER, Regiane. A judicialização da política e a efetividade dos direitos sociais. Revista Eletrônica Direito e Política, Programa de Pós-Graduação Stricto Sensu em Ciência Jurídica da UNIVALI, Itajaí, v.11, n.1, $1^{\circ}$ quadrimestre de 2016. Disponível em: www.univali.br/direitoepolitica - ISSN 19807791.

BRASIL. Constituição da República Federativa do Brasil: promulgada em 5 de outubro de 1988 / obra coletiva de autoria da Editora Saraiva com a colaboração de Antonio Luiz de Toledo Pinto. Marcia Cristina Vaz dos Santos Windt e Lívia Céspedes. 45 ed. atual. e ampl. São Paulo: Saraiva. 2011.

BRASIL. Supremo Tribunal Federal. SL 47 AgR, Relator: Min. Gilmar Mendes (Presidente), Tribunal Pleno, julgado em 17 mar. 2010.

CAMPILONGO, Celso Fernandes. O Judiciário e a democracia no Brasil. Revista USP. São Paulo, n. 21, p. 124 - 125: Coordenadoria de Comunicação Social (CCS) / USP, 1994.

DALLARI, Dalmo de Abreu. O poder dos juízes. São Paulo: Saraiva. 1996. p. 57.

FARIA, José Eduardo. Os desafios do Judiciário. Revista USP. Coordenadoria de Comunicação Social (CCS) / USP, 1994. São Paulo, n. 21, p. 47-57.

GERVASONI, Tássia Aparecida. LEAL, Mônia Clarissa Hennig. Judicialização da política e ativismo judicial na perspectiva do Supremo Tribunal Federal. Curitiba: Multideia, 2013.p. 75.

GRIMM, Dieter. Constituição e política. Tradução de Geraldo de Carvalho. Coordenação e supervisão de Luiz Moreira Belo Horizonte: Del Rey, 2006. p. 3 10.

MORAES, Alexandre de. Direito Constitucional, 26 ed. São Paulo: Atlas, 2010. p. 197

NOVELINO, Marcelo. Manual de Direito Constitucional. 9 Ed. rev. e atual, Rio de Janeiro: Forense; São Paulo: MÉTODO, 2014. p. 619.

NUNES JUNIOR, Amandino Teixeira. A judicialização da política no contexto da Constituição de 1988. In: ARAÚJO, José Cordeiro de; PEREIRA JúNIOR, José de Sena; PEREIRA, Lúcio Soares; RODRIGUES, Ricardo José Pereira (Orgs.). Ensaios sobre impactos da Constituição Federal de 1988 na sociedade brasileira: consultoria legislativa. Brasília: Centro de Documentação e Informação, 2008. p. 755.

SILVA, José Afonso da. Curso de Direito Constitucional Positivo. $30^{a}$ Ed., São Paulo: Malheiros Editores, 2008. p. 285.

STRECK, Lenio Luiz. Jurisdição constitucional e hermenêutica: uma nova crítica do Direito. Porto Alegre: Livraria do Advogado, 2002. p. 105.

TASSINARI. Clarissa. Jurisdição e Ativismo Judicial: limites da atuação do judiciário. Porto Alegre: Livraria do Advogado, 2013. p. 27. 